\title{
Absence of lymphatic vessels in term placenta
}

\author{
Jürgen Becker ${ }^{1}$, Gilles E. Tchagou Tchangou', Sonja Schmidt ${ }^{2}$, Christina Zelent ${ }^{1}$, Fritz Kahl ${ }^{2}$ and Jörg Wilting ${ }^{1 *}$ (D
}

\begin{abstract}
Background: There has been debate about the existence of lymphatic vessels in placenta. Lymphatic endothelial cell (LEC) markers such as LYVE-1 and podoplanin/D2-40 have been found, although PROX1 has not been detected. The most reliable marker for LECs is the double staining for CD31 and PROX1, which has not been performed yet.
\end{abstract}

Methods: We studied three term placentas and dissected them into three areas: i.) basal plate area, ii.) intermediate area, and iii.) chorionic plate area. We used immunofluorescence single and double staining with antibodies against CD31, PROX1, LYVE-1, VEGFR-3, D2-40/PDPN, CD34, CCBE-1, and vimentin, as well as nested PCR, qPCR, Western blot and transmission electron microscopy (TEM).

Results: At TEM level we observed structures that have previously mistakenly been interpreted as lymphatics, however, we did not find any CD31/PROX1 double-positive cells in placenta. Absence of PROX1 was also noted by nested PCR, qPCR and Western blot. Also, LEC marker VEGFR-3 was expressed only in a small number of scattered leukocytes but was absent from vessels. The LEC marker D2-40/PDPN was expressed in most stromal cells, and the LEC marker LYVE-1 was found in a considerable number of stromal cells, but not in endothelial cells, which were positive for CD31, CD34, CCBE-1 and vimentin. Additionally, vimentin was found in stromal cells.

Conclusions: Our studies clearly show absence of lymphatics in term placenta. We also show that the functional area of the mother's endometrium is not penetrated by lymphatics in term pregnancy.

Keywords: Lymphatic endothelial cell - placenta - PROX1 - CCBE1 - PDPN - endometrium - anti-lymphangiogenesis

\section{Background}

Placenta and umbilical cord have been studied extensively during the last decades [1-4], and it is well accepted that the umbilical cord at term contains two arteries and one vein. Knowledge about the umbilical vasculature goes back, at least, to Andreas Vesalius (1514-1564) (for literature see: [5]). Lymphatics have never been found in the umbilical cord. However, the existence of lymphatics in placenta cannot be completely excluded, since not all lymphatics finally reach the jugulo-subclavian angle of the venous system. In the eye,

\footnotetext{
* Correspondence: joerg.wilting@med.uni-goettingen.de

'Deparment of Anatomy and Cell Biology, University Medical School Goettingen, UMG, Kreuzbergring 36, 37075 Göttingen, Germany

Full list of author information is available at the end of the article
}

Schlemm's canal, a lymphatic-like vessel, drains into the vortex veins [6]. The heart, too, contains organ-specific lymphatics, which enter a vein at the base of the organ proper [7]. It could therefore not be excluded that the placenta may contain lymphatics, which do not pass through the umbilical cord, but might directly enter placental veins. In fact, at TEM level, there were descriptions of lymphatics in placental villi [8].

The most reliable marker for staining of lymphatic vessels in human tissues is the double-staining with antibodies against the cell adhesion molecule CD31/ PECAM-1 and the transcription factor PROX1 [9]. Thereby, CD31 is a pan-endothelial marker for both blood vessels and lymphatics, while PROX1 is found specifically in lymphatic endothelial cells (LECs) in

(c) The Author(s). 2020 Open Access This article is licensed under a Creative Commons Attribution 4.0 International License, which permits use, sharing, adaptation, distribution and reproduction in any medium or format, as long as you give appropriate credit to the original author(s) and the source, provide a link to the Creative Commons licence, and indicate if changes were made. The images or other third party material in this article are included in the article's Creative Commons. licence, unless indicated otherwise in a credit line to the material. If material is not included in the article's Creative Commons licence and your intended use is not permitted by statutory regulation or exceeds the permitted use, you will need to obtain permission directly from the copyright holder. To view a copy of this licence, visit http://creativecommons.org/licenses/by/4.0/ The Creative Commons Public Domain Dedication waiver (http://creativecommons.org/publicdomain/zero/1.0/) applies to the data made available in this article, unless otherwise stated in a credit line to the data. 
addition to some non-endothelial cell types, which are CD31-negative $[10,11]$. There are other highly specific LEC markers, which have frequently been used to identify lymphatics: such as the CD44 homolog LYVE-1 [12], the $43 \mathrm{kDa}$ surface glycoprotein podoplanin (PDPN)/ D2-40 [13], 1999), and the Vascular Endothelial Growth Factor Receptor-3 (VEGFR-3 / FLT4) [14-16]. These markers have been used to study human placenta, and thereby, expression of LYVE1 [17] and PDPN/D2-40 has been found $[18,19]$. Thereby, PDPN/D2-40 was observed in the placental stroma, and it was suggested that this may be indicative of a reticular-lymphatic-like conductive system. The expression of D2-40 in stromal cells was also found in another study [20]. These authors also noted absence of PROX1 in fetal placental vessels and, correspondingly, absence of lymphatics in placenta. The above cited studies used immunohistochemistry and peroxidase staining with just single primary antibodies. Here we applied double-immunofluorescence techniques, which is necessary to identify LECs with PROX1 and CD31 antibodies. Additionally, we used other recently described LEC markers such as vimentin and CCBE1 [21], and we performed $\mathrm{qPCR}$ and nested PCR as highly sensitive methods to study expression of PROX1.

\section{Methods}

\section{Tissues and cells}

Three term placentas (week 38, 40, 41) were collected with the informed, written consent of the mothers after normal vaginal births of healthy children, and dissected into three areas: i.) basal plate area, ii.) intermediate area, and iii.) chorionic plate area. Specimens of app. $1 \mathrm{~cm}^{3}$ (and predominantly made up of villous tissue) were rinsed in phosphate buffered saline (PBS) and freshly frozen for Western blot analysis and mRNA isolation for PCR, or fixed for histology and immunohistology as described below. Foreskin specimens from healthy boys were used as positive controls for PCR studies and immunohistology of lymphatic vessels as described [21]. The studies were performed with the informed and written consent of the donors or their legal representatives. Human lymphatic endothelial cells (LECs) were purchased from PromoCell (Heidelberg, Germany), cultured in LEC medium and checked for purity as described recently [22]. All studies on human tissues were approved by the ethics committee of the University Medical Hospital Göttingen, UMG (application no. 18/1/18).

\section{Immunohistology}

For immunofluorescence studies, specimens were fixed for $20-25 \mathrm{~min}$ in $4 \%$ paraformaldehyde (PFA), rinsed in PBS, transferred into 10 and 30\% sucrose in PBS, and embedded in tissue freeze medium (Tissue Tek, Sakura
Finetek Zoeterwoude, NL). Sections of $12-14 \mu \mathrm{m}$ were incubated with the following primary antibodies: Rabbitanti-human CCBE1 (1:500, Sigma-Aldrich, München, Germany; \#R38605), mouse-anti-human CD31 (1:50, BD Pharmingen; clone WM59), mouse-anti-human D2-40/ podoplanin (1:200, Dako, Hamburg, Germany; \#M3619), rabbit-anti-human LYVE-1 (1:500, ReliaTech, Wolfenbüttel, Germany; \#102-PA50AG), rabbit-anti-human PROX1 (1:500, ReliaTech; \#102-PA32AG), mouse-antihuman vimentin (1:200, Dako; \#GA630), mouse-antihuman CD34 (1:200, Dako; clone QBEnd-10), mouseanti-human VEGFR-3 (1:100, ReliaTech; \#101-M36). Secondary antibodies were: goat-anti-mouse Alexa 488/ 594 (\#A11001; \#A21135), goat-anti-rabbit Alexa 594 (\#A11012), donkey-anti-goat Alexa 488 (\#A11055; MobiTech, Göttingen, Germany). Sections were counterstained with Dapi and mounted under cover slips with Fluoromount-G (Southern Biotechnology, US). Photos were taken with AxioImagerZ1 (Zeiss, Göttingen, Germany).

\section{Transmission electron microscopy (TEM)}

Specimens were fixed with original Karnovsky's fixative over-night [23], washed in $0.15 \mathrm{M}$ phosphate buffer for $10 \mathrm{~min}$, transferred into osmium tetroxide solution and incubated for $2 \mathrm{~h}$ at $4{ }^{\circ} \mathrm{C}$. Then the samples were rinsed with $0.15 \mathrm{M}$ phosphate buffer for $10 \mathrm{~min}$ and subsequently dehydrated in an ascending series of ethanol. Samples were transferred into Epon embedding solution, cut with an Ultracut E microtome (Reichert-Jung) into $90 \mathrm{~nm}$ sections. Staining of sections was performed as described [21]. Specimens were analyzed with Leo 906E TEM (Zeiss, Germany).

\section{Western blot}

Cells and tissues were washed 3-times with DPBS (Pan Biotech; Aidenbach, Germany) and $1 \mathrm{mM}$ sodium orthovanadate (Sigma-Aldrich; Steinheim, Germany), homogenized (tissues), and subsequently lysed with RIPA buffer for $10 \mathrm{~min}$ on ice. Samples were transferred to micro-tubes (Sarstedt; Nürnberg, Germany) and centrifuged by $20,800 x$ g for $15 \mathrm{~min}$. Protein lysates were collected and used for SDS-PAGE according to standard procedures. Proteins were transferred to PVDF membranes (Roth; Karlsruhe, Germany), which were then washed with TBST $(0.1 \%$ Tween 20$)$ for $10 \mathrm{~min}$ and blocked for $1 \mathrm{~h}$ in blocking buffer (5\% BSA in TBST $0.1 \%)$. Primary anti-human antibodies were: Lyve1 (ReliaTech, Lot 1408R07), PROX1 (Reliatech Lot 0810R19-1), VEGFR-3/FLT4 (ReliaTech, Lot \#9D9) and peroxidase-conjugated $\alpha$-tubulin, 1:10000 (Abcam, ab40742). Incubation was at $4{ }^{\circ} \mathrm{C}$ overnight. After washing with TBST $(0.1 \%$ Tween 20$)$ for $10 \mathrm{~min}$., the peroxidase-conjugated secondary anti-rabbit IgG, 1:2000 


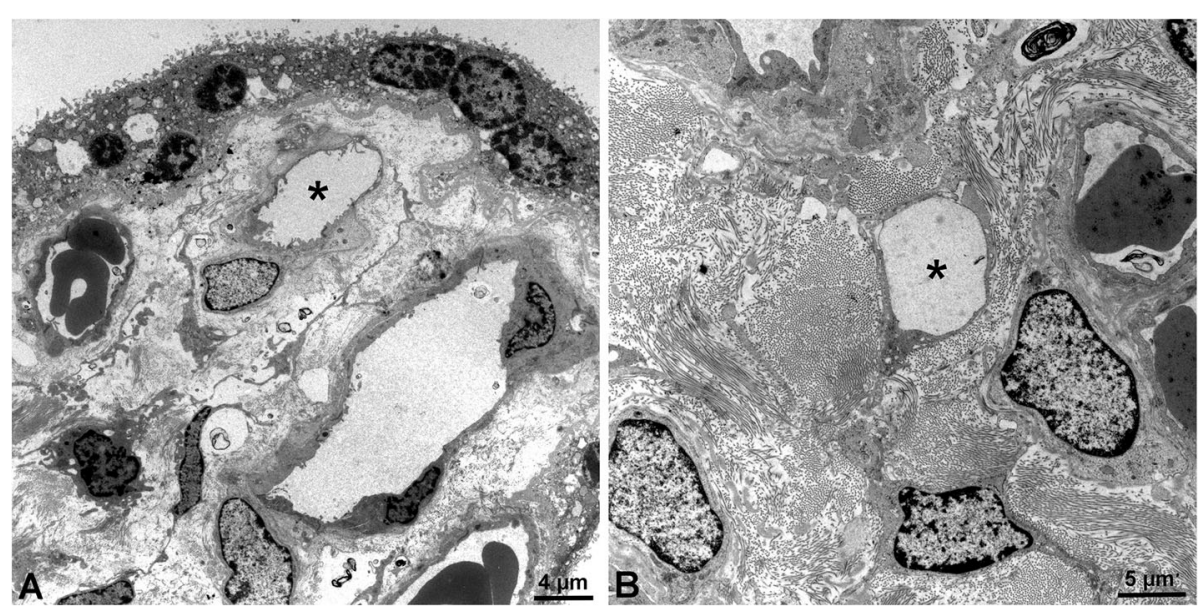

Fig. 1 TEM studies of term placentas. a, b) The chorionic villi are typically made up of syncytiotrophoblast, some cytotrophoblast cells, blood capillaries and stromal cells. Asterisks mark huge vacuolated cells

(Santa Cruz; USA) were incubated for $1 \mathrm{~h}$. After washing, antigen-antibody complexes were visualized with ECL in Chemidoc Touch Imaging System (Bio-Rad, München, Germany).

\section{Real-time RT-PCR}

Real Time RT-PCR was performed as described [24]. Primers were:

PROX1_fwd: 5'-tgaatccccaaggttctgag-3', Prox1_rev: 5' -agcagcttgcggagtacatt-3', LYVE-1_fwd: 5' -gctttccatcca ggtgtcat-3', Lyve-1_rev: 5' -agcctacaggcctccttagc-3', Podoplanin_fwd: 5'-gaagacatccccagtcctca-3', Podoplanin_rev: $5^{\prime}$-ctggatggtgctgagacaga-3'. Relative expression was calculated in comparison to LEC expression levels by using the $\delta \delta C T-M e t h o d$ [25]. Statistical analyses were conducted by two-way-ANOVA with STATISTICA software (Statsoft, Tulsa, Oklahoma). Normal distribution was verified before testing. The standard error of the mean (SEM) was calculated and is shown in the graphs.
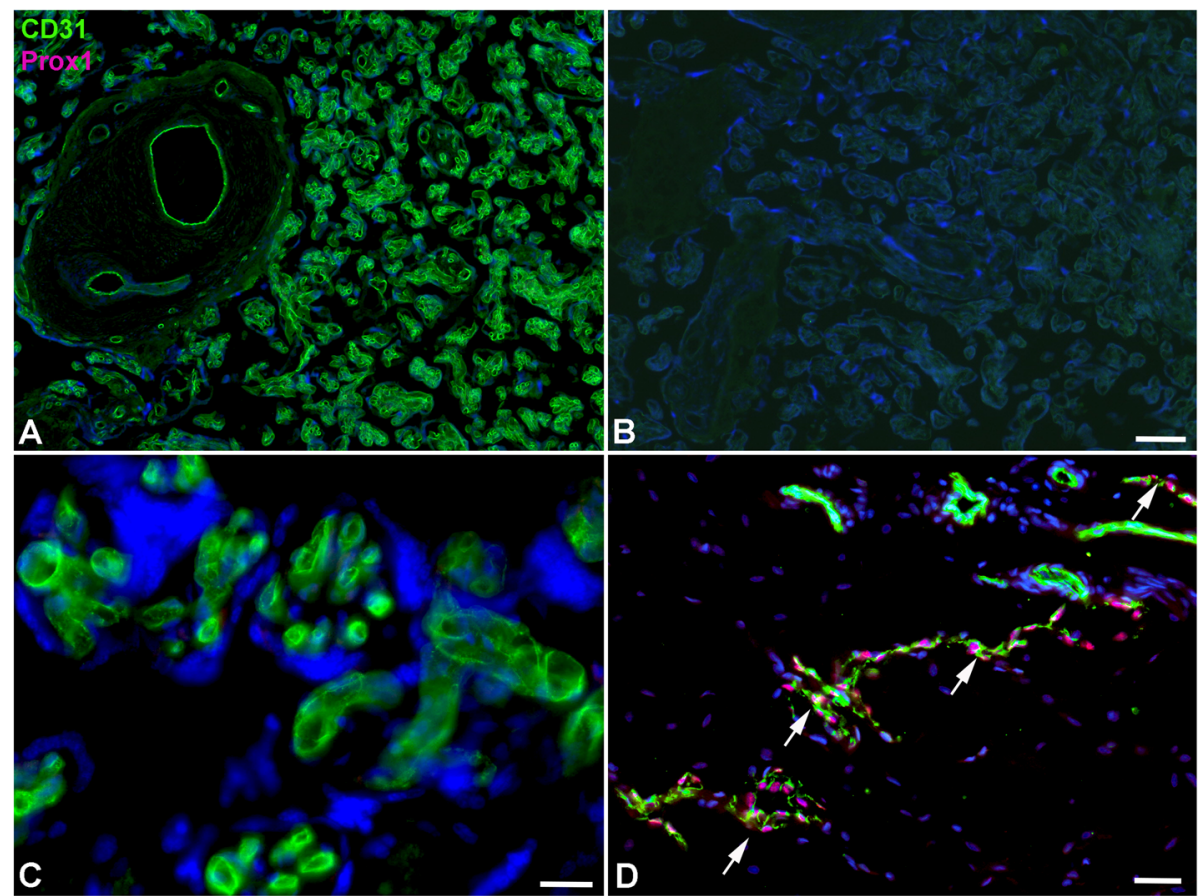

Fig. 2 Anti-CD31 (green) and anti-PROX1 (magenta) double-staining of delivered placenta (A-C) and fore-skin (D). a CD31 marks all blood vessels in the placenta. b Negative control without primary antibody. $\mathbf{c}$ Higher magnification of A). Note absence of PROX1 in placental vessels. $\mathbf{d}$ Foreskin (as positive control) contains a dense network of lymphatics (arrows). Bar $=100 \mu \mathrm{m}$ in A,B; $15 \mu \mathrm{m}$ in C, and $35 \mu \mathrm{m}$ in D 


\section{Nested RT-PCR}

Nested PCR was performed to increase specificity and reduce non-specific binding of primers, starting with 40 cycles with outer primers (out) followed by inner primers (in). Primers were:

Prox1_out_fwd: 5'-gtcatctcaccacctgagcc-3'; Prox1_ out_rev: 5 '-tggaacctcaaagtcatttgct-3'.

Prox1_in_fwd: 5' -gagtgcggcgatcttcaa-3'; Prox1_in_rev: 5 '-ggtgacaatccttcctgcat-3'.

\section{Results}

Our TEM studies revealed typical characteristics of the term placenta with syncytiotrophoblast, sparse cytotrophoblast, fetal capillaries and stromal cells (Fig. 1), but also cells with huge vacuoles (asterisks in Fig. 1), which have been taken as a hint for the existence of lymphatics [8], but may be signs of disintegration of tissue after delivery of the placenta. There is no cell membrane lining the vacuoles, and there is no basal lamina, which would be characteristic of capillaries. Searching for lymphatics in the placenta we performed anti-CD31 and antiPROX1 double-staining. In contrast to dermis, which contains a dense lymphatic network, we never observed lymphatics in the placenta (Fig. 2). The absence of PROX1 was confirmed by qPCR (Fig. 3), nested PCR (Fig. 4) and Western blot (Fig. 5). We compared three areas of the placenta (basal plate area, intermediate area, and chorionic plate area) with pure LECs, and with both LECs as well as foreskin tissue. As expected, LECs were clearly positive for PROX1, whereas no signal was found in placenta (Figs. 3, 4, 5). Also, with nested PCR the signal was highest in LECs and a lower signal was found in foreskin. Again, no signal was detectable in placenta from all three selected areas (Fig. 4). Absence of lymphatics in placenta was confirmed by anti-VEGFR-3 staining. We observed a signal in a very small number of scattered leukocytes, but not in endothelial cells (Fig. 6a-c). Accordingly, a signal for VEGFR-3 was not detectable in placenta with Western blot (Fig. 5). The LEC marker LYVE1 was found in scattered stromal cells of the placenta, and there was no colocalization with the endothelial marker CD34 (Fig. 6 d-f). LYVE1 was well detectable in placenta with qPCR and Western blot (Figs. 3, 5). The LEC marker D2-40/PDPN was detected in almost all stromal cells of the placenta, and again, there was no colocalization with the endothelially expressed CCBE1 (Fig. 6 g-i). With qPCR we found high levels of PDPN expression in placenta (Fig. 3). Vimentin, a typical mesenchymal marker was found in endothelial cells and stromal cells (Fig. $6 \mathrm{k}-\mathrm{m}$ ). Our data reveal that none of the characteristic LEC markers (PROX1, VEGFR-3, LYVE1, and PDPN) is expressed in endothelial cells of the placenta; and PROX1, the probably most important marker, is completely absent from placenta.

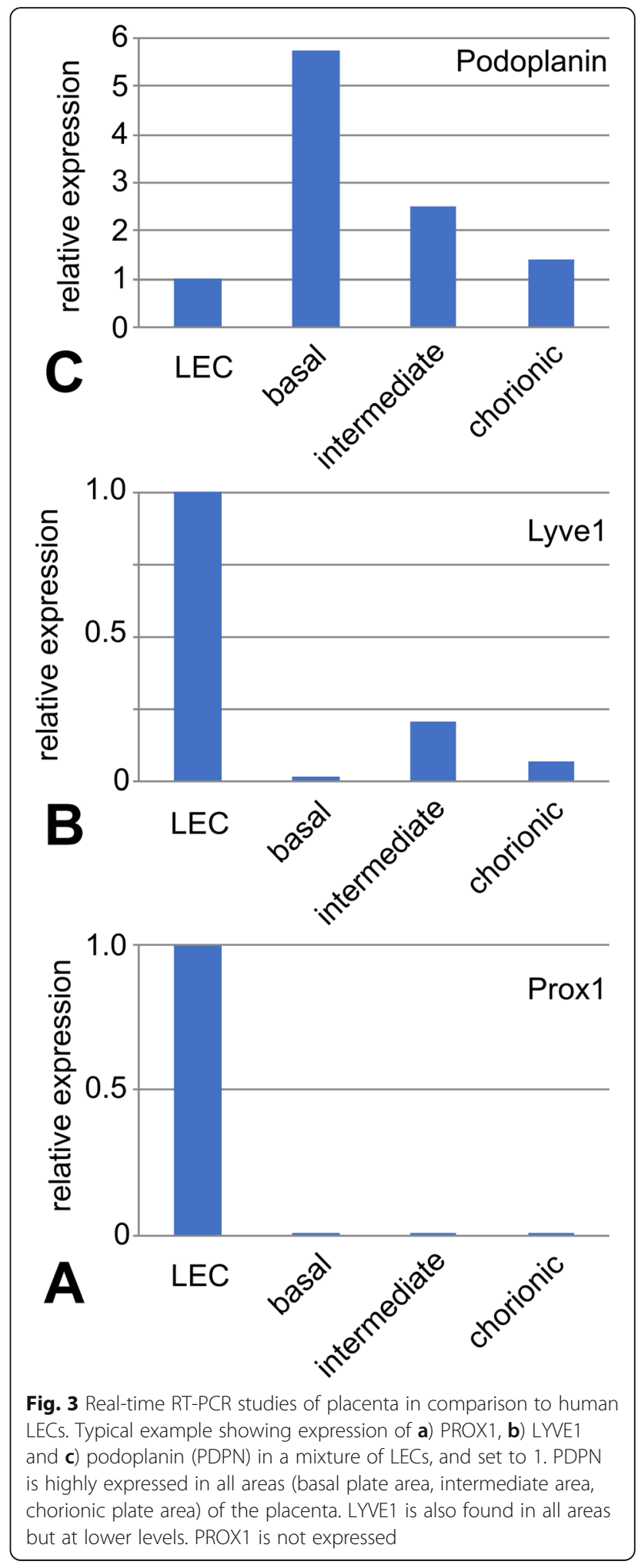

\section{Discussion}

Lymphatics in placenta

The discussion about the existence of lymphatics in the placenta was refueled by the description of reticular 


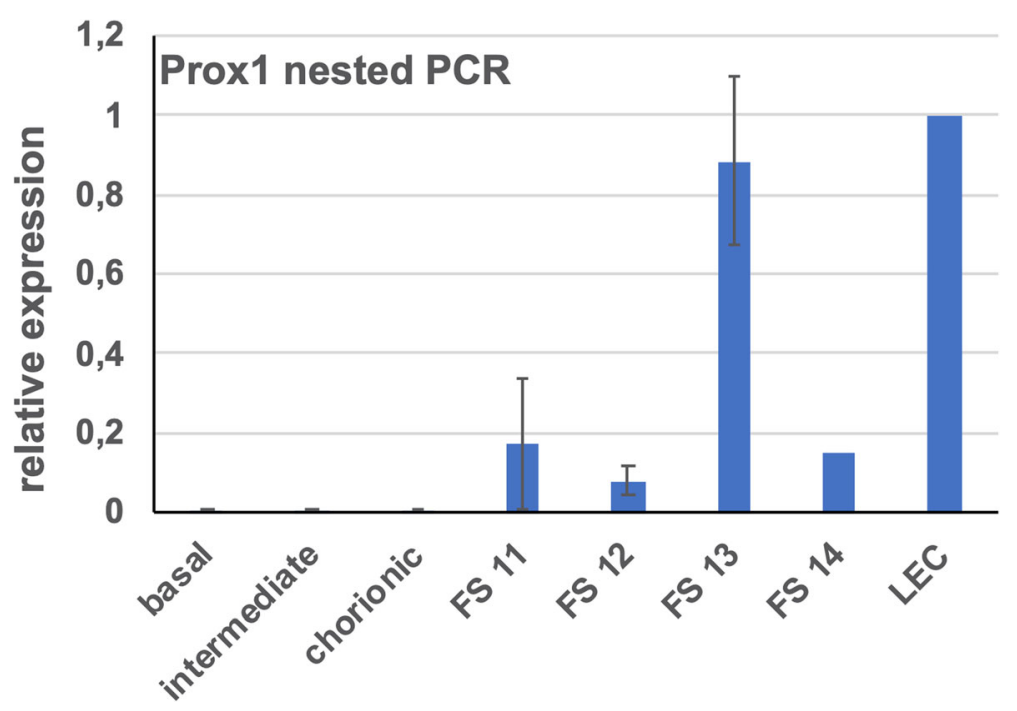

Fig. 4 Nested PCR comparing PROX1 expression in placenta, foreskin and LECs. PROX1 expression in a mixture of LECs was set to 1. Note that there is a clear signal in foreskin specimens (FS11-14), while no signal is found in placenta (basal plate area, intermediate area, chorionic plate area)

lymphatic-like D2-40/PDPN-positive networks [19]. Previously, at TEM level, vessel-like structures had been described that appeared to be lymphatics [8]. At TEM level, however, lymphatics can only be identified by the characteristic overlapping junctions between LECs, which represent valves, and are associated with anchoring filaments that connect the outer valvular leaflet with adjoining collagen fibers or fibrocytes [26]. We did not detect such ultrastructural characteristics and suggest that the lymphatics described previously in the placenta [8] may represent signs of massive intracellular fluid accumulation. In our eyes, the immuno-histological studies on PDPN shown by Bellini et al. 2012 [19] are not

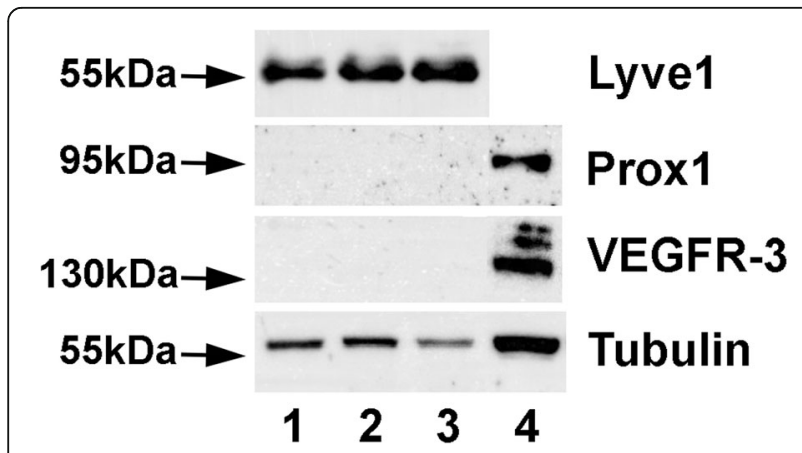

Fig. 5 Western blot analysis of placenta (lanes 1-3) in comparison to a mixture of human LECs (lane 4) with antibodies against LYVE1, PROX1, VEGFR-3, and a-tubulin as a housekeeper protein. Lane 1 basal plate area; lane 2 - intermediate area; lane 3 - chorionic plate area; lane4 - LECs. LYVE1 is expressed in placenta, but PROX1 and VEGFR-3 are not detectable convincing. Nevertheless, PDPN expression in placenta has also been shown by others [18, 20]. Again, these studies used single immunohistochemical staining of placentas, not double immunofluorescence of LEC makers. We therefore reinvestigated this topic. We used well-known and newly identified BEC and LEC markers. We show that placental endothelial cells are positive for CD31, CD34, CCBE-1 and vimentin. There is no coexpression of PROX1 in $\mathrm{CD}^{+} 1^{+}$vessels, no coexpression of LYVE1 in $\mathrm{CD}_{3} 4^{+}$vessels, and no coexpression of $\mathrm{D} 2-40$ in $\mathrm{CCBE}^{+}$vessels. These data, together with the non-detectable PROX1 PCR signal, clearly show the absence of lymphatics in placenta.

We show that LYVE1 is expressed in a distinct subpopulation of stromal cells. These cells may, at least in part, represent macrophages, as shown in embryonic and adult tissues [27-29]. D2-40 is expressed in the majority of villous stromal cells, arguing against a specific reticular lymphatic-like system in term placenta. The relation between the intercellular (pre-lymphatic) spaces and the lymphatic vascular system was seminally studied by Friedrich Daniel von Recklinghausen (1862) [30]. Generally, we recommend that the term lymphatic vascular system (lymphatics) should be restricted to a system lined by LECs. This also applies to the para-vascular (Virchow Robin) spaces in the central nervous system, which have been designated glymphatics [31]. In sum, our data confirm the findings by Castro et al. (2011) [20] on the non-existence of lymphatics in term placenta, extend previous studies on the expression of vimentin and CCBE1 in endothelial cells [21], and challenge the existence of a reticular lymphatic-like system in the stroma 


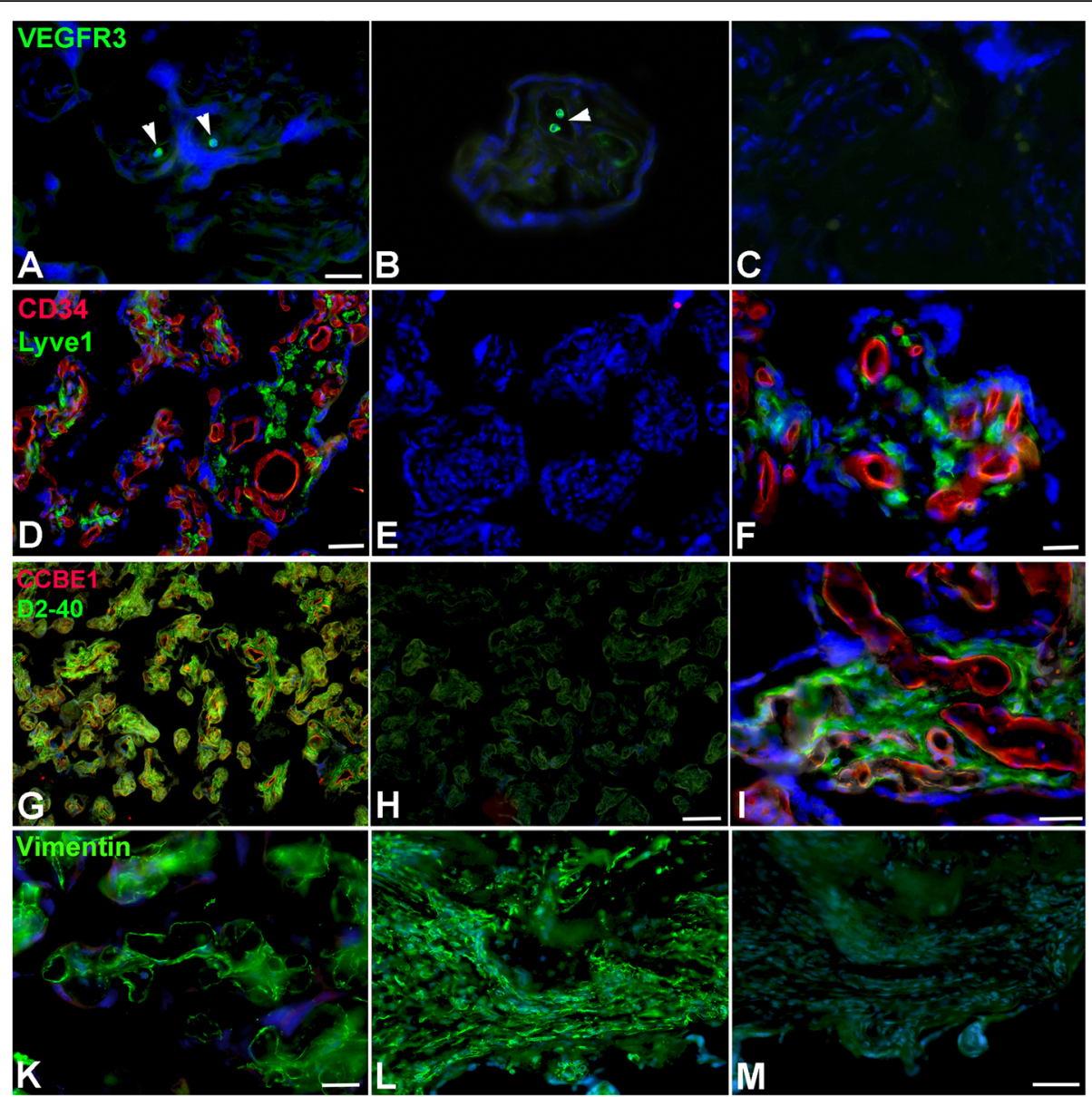

Fig. 6 Immunofluorescence staining of term placenta with various antibodies. Counter-staining of nuclei with Dapi (blue). a-c) VEGFR-3 (green) is expressed in a few intra- and extra-vascular leukocytes (arrowheads in A,B). Bar $=35 \mu \mathrm{m}$. C) Negative control without primary antibody. d-f) CD34 (red) and LYVE1 (green) double-staining. CD34 is expressed in endothelial cells, LYVE1 in scattered stromal cells. E) Negative control without primary antibody. Bar $=120 \mu \mathrm{m}$ in D, and $30 \mu \mathrm{m}$ in F. g-i) CCBE1 (red) and D2-40/PDPN (green) double-staining. CCBE1 is expressed in endothelial cells, PDPN in numerous stromal cells. H) Negative control without primary antibody. Bar $=120 \mu \mathrm{m}$ in $\mathrm{H}$, and $30 \mu \mathrm{m}$ in I. k-m) Vimentin is expressed in endothelial cells and stromal cells of terminal villi $(K)$ and stem villi $(L)$. M) Negative control without primary antibody. Bar $=30 \mu \mathrm{m}$ in $\mathrm{K}$, and $120 \mu \mathrm{m}$ in $\mathrm{M}$

of term placenta [19]. However, studies on first and second trimester placenta seem to be useful to obtain a more complete view of lymphatic functions in this rapidly changing organ.

\section{Lymphatics in endometrium}

We collected term placentas and dissected them into three areas: i.) basal plate area, ii.) intermediate area, and iii.) chorionic plate area. We expected that the basal plate area might differ from the others with respect to the expression of LEC markers, especially PROX1. However, even with nested PCR, we did not observe significant differences. The basal plate area contains (a small portion of) functional maternal tissue, and it has been shown that the endometrial stroma is invaded by lymphatics (for review see: [32]). It has been estimated that 13 and $43 \%$ of vessels in the functional and basal layers of the endometrium, respectively, are lymphatics [33]. Thereby, close association of lymphatics with spiral arterioles was observed. Interestingly, anti-lymphangiogenesis seems to occur during decidualization. PDPN-positive lymphatics have been found in non-decidualized hypersecretory endometrium, in clear contrast to the more superficial decidualized areas [34]. Our data seem to be in line with these findings. The decidua accomplishes roles, among others, in maternal tolerance. In mice, endometrial dendritic cells become trapped during decidualization and lose their potency to migrate into uterine lymphatics and lymph nodes [35]. Anti-lymphangiogenesis in decidualized human endometrium may act in the same functional direction, and may thereby support immune tolerance of the fetal allograft. Rodent endometrium, however, does not contain lymphatics [32], limiting functional studies on this system. In the human, interactions of trophoblast cells 
with lymphatics have been observed in the first trimester of pregnancy [36]. There, extravillous trophoblast cells invade the wall of arteries and veins to almost the same high extent, while lymphatics are invaded less often. Intraluminal trophoblast cells are found in maternal veins and lymphatics, and, with the latter, may reach the regional lymph nodes. The functional significance of these interactions remains to be studied, however, in recurrent spontaneous abortion the number of trophoblast-affected lymphatics is significantly reduced [36]. The invasion of trophoblast cells into lymphatics takes place even before the trophoblast cells remodel the spiral arteries in the decidua [37], which seems to be in line with the hypothesis that immunomodulation is an early aspect of pregnancy, while later endometrial lymphatics may lose their functional significance.

\section{Conclusions}

Our studies provide clear evidence for the absence of lymphatics in term placenta. Although some LEC markers are highly expressed in placenta, none of these markers is colocalized to endothelial cells. The transcription factor PROX1, which is essential for the development and maintenance of lymphatics, is not expressed in term placenta, neither at protein nor at RNA level. The placenta obviously possesses other mechanisms to handle typical homeostatic functions of the lymphatic vasculature. We could also not detect PROX1 expression in endometrial tissue associated with the placenta specimens. While in the first trimester the endometrial lymphatics seem to have important functions for the establishment of mother's immunosuppressive mechanisms [36, 37], the importance of lymphatics may become reduced during maturation. If this is accompanied by anti-lymphangiogenesis in decidualized endometrium must be tested comparatively on a larger number of samples.

\section{Supplementary information}

Supplementary information accompanies this paper at https://doi.org/10. 1186/s12884-020-03073-W.

Additional file 1.

\section{Abbreviations}

BEC: Blood vascular endothelial cell; CCBE1: Collagen and calcium binding EGF domains 1; CD31/PECAM-1: Platelet endothelial adhesion molecule-1; CD34: CD34 molecule; EGM-2: Endothelial growth medium-2; LEC: Lymphatic endothelial cell; LYVE-1: Lymphatic vessel endothelial hyaluronic acid receptor-1; PBS: Phosphate-buffered saline; PDPN: Podoplanin (D2-40); PROX1: Prospero-related homeobox transcription factor-1; TEM: Transmission electron microscope/microscopy; VEGF-C: Vascular endothelial growth factorC; VEGFR-3: Vascular endothelial growth factor receptor-3 / FLT4

\section{Acknowledgments}

We are grateful to S. Schwoch and B. Manshausen for their excellent technical assistance.

\section{Authors' contributions}

GETT: Performed immunofluorescence, Western blot, TEM and APCR; JB: Supervision of studies, data evaluation, writing draft; CZ: Performed QPCR, nested PCR and collected specimens; SS and FK performed acquisition of specimens; JW: Study design, data evaluation, writing draft and final version. All authors agree to the publication of the manuscript. The author(s) read and approved the final manuscript.

\section{Funding}

The studies were supported by the Verein zur Förderung der Lymphologie e.V., Hinterzarten, Germany. The grant supplier did not have any influence on the performance of the studies.

\section{Availability of data and materials}

All data generated or analyzed during this study are included in this published article and the supplementary information files. Original qPCR data can be sent upon request.

\section{Ethics approval and consent to participate}

All tissue donors gave their informed and written consent to the studies. The studies were approved by the ethics committee of the University Medical Hospital Göttingen, UMG (application no.: 18/1/18).

\section{Consent for publication}

Not applicable.

\section{Competing interests}

The authors have no conflicts of interest relevant to this article to disclose.

\section{Author details}

'Deparment of Anatomy and Cell Biology, University Medical School Goettingen, UMG, Kreuzbergring 36, 37075 Göttingen, Germany.

${ }^{2}$ Department of General-, Visceral- and Pediatric Surgery, University Medical Center Goettingen, UMG, Göttingen, Germany.

Received: 28 June 2019 Accepted: 22 June 2020

Published online: 29 June 2020

\section{References}

1. Sauramo H. Histology of the placenta in normal, premature, and over-term cases, and in gestosis. Ann Chir Gynaecol Fenn. 1951;40:164-88.

2. Boyd JD, Hughes AFW. Observations on human chorionic villi using the electron microscope. J Anat. 1954:88(Pt 3):356-362.3.

3. Lyon FA. Fetal abnormalities associated with umbilical cords containing one umbilical artery and one umbilical vein. Obstet Gynecol. 1960;16:719.

4. Fox H. Haemangiomata of the placenta. J Clin Pathol. 1966;19:133-7.

5. Faierman E. The significance of one umbilical artery. Arch Dis Child. 1960;35: 285-8.

6. Park D-Y, Lee J, Park I, Choi D, Lee S, Song S, et al. Lymphatic regulator PROX1 determines Schlemm's canal integrity and identity. J Clin Invest. 2014;124:3960-74.

7. Wilting J, Buttler K, Schulte I, Papoutsi M, Schweigerer L, Männer J. The proepicardium delivers hemangioblasts but not lymphangioblasts to the developing heart. Dev Biol. 2007;305:451-9.

8. Rhodin JAG. Histology: a text and atlas. New York: Oxford University Press; 1977.

9. Wilting J, Papoutsi M, Christ B, Nicolaides KH, von Kaisenberg CS, Borges J, et al. The transcription factor Prox 1 is a marker for lymphatic endothelial cells in normal and diseased human tissues. FASEB J. 2002;16:1271-3.

10. Wigle JT, Oliver G. Prox 1 function is required for the development of the murine lymphatic system. Cell. 1999;98:769-78.

11. Rodriguez-Niedenfuhr M, Papoutsi M, Christ B, Nicolaides $\mathrm{KH}$, von Kaisenberg CS, Tomarev SI, et al. Prox1 is a marker of ectodermal placodes, endodermal compartments, lymphatic endothelium and lymphangioblasts. Anat Embryol (Berl). 2001;204:399-406.

12. Banerji S, Ni J, Wang S-X, Clasper S, Su J, Tammi R, et al. LYVE-1, a new homologue of the CD44 glycoprotein, is a lymph-specific receptor for Hyaluronan. J Cell Biol. 1999;144:789-801.

13. Breiteneder-Geleff S, Soleiman A, Kowalski H, Horvat R, Amann G, Kriehuber $E$, et al. Angiosarcomas express mixed endothelial phenotypes of blood and 
lymphatic capillaries: Podoplanin as a specific marker for lymphatic endothelium. Am J Pathol. 1999;154:385-94.

14. Kaipainen A, Korhonen J, Pajusola K, Aprelikova O, Persico MG, Terman BI, et al. The related FLT4, FLT1, and KDR receptor tyrosine kinases show distinct expression patterns in human fetal endothelial cells. J Exp Med. 1993;178:2077-88.

15. Wilting J, Brand-Saberi B, Kurz H, Christ B. Development of the embryonic vascular system. Cell Mol Biol Res. 1995;41:219-32.

16. Oh SJ, Jeltsch MM, Birkenhager R, McCarthy JE, Weich HA, Christ B, et al. VEGF and VEGF-C: specific induction of angiogenesis and lymphangiogenesis in the differentiated avian chorioallantoic membrane. Dev Biol. 1997;188:96-109.

17. Gu B, Alexander JS, Gu Y, Zhang Y, Lewis DF, Wang Y. Expression of lymphatic vascular endothelial Hyaluronan Receptor-1 (LYVE-1) in the human placenta. Lymphat Res Biol. 2006;4:11-7.

18. Wang Y, Sun J, Gu Y, Zhao S, Groome L, Alexander JS. D2-40/podoplanin expression in the human placenta. Placenta. 2011;32:27-32.

19. Bellini C, Rutigliani M, Boccardo F, Campisi C, Bellini T, Bonioli E, et al. Are there lymphatic vessels in the placenta? Lymphology. 2012;45:34-6.

20. Castro E, Tony Parks W, Galambos C. Neither normal nor diseased placentas contain lymphatic vessels. Placenta. 2011;32:310-6.

21. Hasselhof V, Sperling A, Buttler K, Strobel P, Becker J, Aung T, et al. Morphological and molecular characterization of human dermal lymphatic collectors. PLoS One. 2016;11:e0164964.

22. Blesinger H, Kaulfuss S, Aung T, Schwoch S, Prantl L, Rossler J, et al. PIK3CA mutations are specifically localized to lymphatic endothelial cells of lymphatic malformations. PLoS One. 2018;13:e0200343.

23. Karnovsky M. A formaldehyde-glutaraldehyde fixative of high osmolality for use in electron microscopy. J Cell Biol. 1965;27:137a.

24. Becker J, Erdlenbruch B, Noskova I, Schramm A, Aumailley M, Schorderet DF, et al. Keratoepithelin suppresses the progression of experimental human neuroblastomas. Cancer Res. 2006;66:5314-21.

25. Livak KJ, Schmittgen TD. Analysis of relative gene expression data using real-time quantitative PCR and the 2- $\Delta \Delta C T$ method. Methods. 2001;25:402-8.

26. Leak LV, Burke JF. Ultrastructural studies on the lymphatic anchoring filaments. J Cell Biol. 1968:36:129-49.

27. Wilting J, Aref Y, Huang R, Tomarev SI, Schweigerer L, Christ B, et al. Dual origin of avian lymphatics. Dev Biol. 2006;292:165-73.

28. Buttler K, Ezaki T, Wilting J. Proliferating mesodermal cells in murine embryos exhibiting macrophage and lymphendothelial characteristics. BMC Dev Biol. 2008;8:43.

29. Chakarov S, Lim HY, Tan L, Lim SY, See P, Lum J, et al. Two distinct interstitial macrophage populations coexist across tissues in specific subtissular niches. Science. 2019:363:eaau0964.

30. von Recklinghausen FD. Die Lymphgefäße und ihre Beziehung zum Bindegewebe. 1862. https://archive.org/details/dielymphgefsseu00reckgoog/ page/n9.

31. Nliff JJ, Wang M, Liao Y, Plogg BA, Peng W, Gundersen GA, et al. A paravascular pathway facilitates CSF flow through the brain parenchyma and the clearance of interstitial solutes, including amyloid $\beta$. Sci Transl Med. 2012:4:147ra111.

32. Girling JE, Rogers PAW. The endometrial lymphatic vasculature: function and dysfunction. Rev Endocr Metab Disord. 2012;13:265-75.

33. Donoghue JF, Lederman FL, Susil BJ, Rogers PAW. Lymphangiogensis of normal endometrium and endometrial adenocarcinoma. Hum Reprod. 2007; 22:1705-13.

34. Volchek M, Girling JE, Lash GE, Cann L, Kumar B, Robson SC, et al. Lymphatics in the human endometrium disappear during decidualization. Hum Reprod. 2010;25:2455-64.

35. Collins MK, Tay C-S, Erlebacher A. Dendritic cell entrapment within the pregnant uterus inhibits immune surveillance of the maternal/fetal interface in mice. J Clin Invest. 2009;119:2062-73.

36. Windsperger K, Dekan S, Pils S, Golletz C, Kunihs V, Fiala C, Kristiansen G, Knöfler M, Pollheimer J. Extravillous trophoblast invasion of venous as well as lymphatic vessels is altered in idiopathic, recurrent, spontaneous abortions. Hum Reprod. 2017;32:1208-17.

37. He N, van Iperen L, de Jong D, Szuhai K, Helmerhorst FM, van der Westerlaken LA, Chuva de Sousa Lopes SM. Human extravillous trophoblasts penetrate decidual veins and lymphatics before remodeling spiral arteries during early pregnancy. PLoS One. 2017;12:e0169849.

\section{Publisher's Note}

Springer Nature remains neutral with regard to jurisdictional claims in published maps and institutional affiliations.
Ready to submit your research? Choose BMC and benefit from:

- fast, convenient online submission

- thorough peer review by experienced researchers in your field

- rapid publication on acceptance

- support for research data, including large and complex data types

- gold Open Access which fosters wider collaboration and increased citations

- maximum visibility for your research: over $100 \mathrm{M}$ website views per year

At BMC, research is always in progress.

Learn more biomedcentral.com/submissions 